\title{
Vivências de gestantes e puérperas com o diagnóstico do HIV
}

\author{
Experiences of pregnant and post-partum women with HIV \\ Experiencias de mujeres embarazadas y en el postparto con diagnóstico de HIV
}

\author{
Maria Alix Leite Araújo', Cláudia Bastos da Silveira", \\ Caroline Bastos da Silveira'", Simone Paes de Melo' \\ 'Universidade de Fortaleza. Curso de Enfermagem. Fortaleza, CE \\ "Hospital Geral de Fortaleza. Fortaleza, CE \\ IIIPrograma de Saúde da Família. Petencoste, CE
}

Submissão: 25/07/2007

Aprovação: 18/09/2008

\section{RESUMO}

Identificar as experiências de gestantes e puérperas portadoras do HIV com a Quimioprofilaxia para prevenção da transmissão vertical. Estudo de abordagem Qualitativa desenvolvido nos meses de março e abril de 2006 em uma maternidade de referência de Fortaleza-Ceará. Os sujeitos foram gestantes e puérperas HIV positivas em acompanhamento pré-natal e no alojamento conjunto. A coleta de dados deuse através de entrevista e a análise em três categorias: a revelação do diagnóstico aos familiares, o aconselhamento e a vivência das recomendações para a profilaxia da transmissão vertical. Constatou-se Que essas mulheres enfrentaram situações de conflitos e sentimentos negativos diante da vida e a importância do acompanhamento emocional por equipe multiprofissional capacitada, atenta as demandas subjetivas.

Descritores: Assistência pré-natal; Sorodiagnóstico da AIDS; Quimioprofilaxia; Enfermagem.

\begin{abstract}
Detect the experiences of pregnants and mothers that bear the HIV viruses using Quimioprophylaxlis to prevent the upright transmission. A research of Qualitative approach developed between march and april of 2006 on main mother-hoods in Fortaleza - Ceará. The persons were pregnants and mothers with positive HIV in the accompaniment and in the accommodations. The colect of informations happened with interviews appointments and analisys in three categories: the revelations of diagnosis to relatives, the advice and how live these persons with the advices to profilaxy of the upright transmission. We can see these women fought against conflicts and negative fellings in their lives and a individualize accompaniment by a capacitate team minimizes the emotional side of the patients.
\end{abstract}

Descriptors: Prenatal care; AIDS Serodiagnosis; Chemoprenvention; Nursing.

\section{RESUMEN}

Identificar las experiencias de las embarazadas y madres recientes portadoras de HIV con la Quimioprofilaxia para la prevención de la transmisión vertical. Estudio de abordaje cualitativo desarrollado entre los meses de marzo y abril de año 2006, en maternidad importante de Fortaleza/CE. Las personas fueron embarazadas y madres recientes HIV positivas en acompañamiento prenatal y en alojamiento conjunto. La colecta de datos ocurrió a través de entrevista y análisis en tres categorías: La revelación del diagnóstico a los familiares, el consejo y la vida de las recomendaciones para la profilaxia de las transmisión vertical. Constatase Que las mujeres enfrentan situaciones de conflictos y sentimientos negativos delante de la vida y que el acompañamiento individual por una equipo de múltiplos profesionales capacitadas diminuye mucho su estado emocional.

Descriptores: Asistencia prenatal; Sorodiagnóstico de la AIDS; Quimioprevención; Enfermería.

Correspondência: Maria Alix Leite Araújo. Universidade de Fortaleza. Curso de Enfermagem. Av Washington Soares I321. CEP 6084I-030. Fortaleza, CE. 


\section{INTRODUÇÃO}

O aumento no número de mulheres com Aids trouxe como conseQüência o crescimento nas taxas de transmissão vertical (TV) do Vírus da Imunodeficiência Humana (HIV) (1). Essa situação provocou a infecção de percentual considerável de crianças em todo o mundo com o vírus HIV, devido ao fato de que muitas das mulheres com Aids encontram-se em idade reprodutiva ${ }^{(1)}$.

Estimativas do Ministério da Saúde (MS) apontam que, a cada ano, 17.200 gestantes são infectadas pelo HIV, fazendo com Que a TV seja responsável por praticamente todos os casos da infecção em crianças menores de 13 anos $^{(2)}$. A maioria dessas transmissões ocorre durante o trabalho de parto e parto propriamente dito, outras ocorrem intra-útero, especialmente nas últimas semanas de gestação. O aleitamento materno representa risco adicional de transmissão de $7 \%$ a $22 \%{ }^{(2)}$

É crucial para a saúde dessas crianças a identificação precoce do HIV nas gestantes ainda durante o pré-natal, para Que haja tempo hábil de realizar a Quimioprofilaxia para prevenção da TV e diminuição drástica da possibilidade de transmissão para o bebê. Porém, o que se evidencia na prática é um Quantitativo considerável de mulheres Que mesmo tendo o diagnóstico durante o pré-natal, chegam às maternidades em trabalho de parto sem ter recebido o tratamento anti-retroviral. Esse problema é decorrente da falta de cobertura adequada de testagem do HIV em gestantes na atenção básica ${ }^{(3)}$.

A partir de um estudo Que comprovou que o uso da Zidovudina (AZT) em mulheres grávidas HIV positivas durante o pré-natal e no momento do parto e, no bebê, durante as seis primeiras semanas de vida (Protocolo 076), reduziu em dois terços a transmissão do vírus para as crianças $^{(4)}$, o Ministério da Saúde propôs a inserção do aconselhamento e diagnóstico do HIV na rotina do atendimento prénatal. Este estudo foi considerado um dos mais importantes na área de prevenção da TV e mostrou a possibilidade de prevenção da infecção no bebê, Quando as gestantes são identificadas e tratadas adequadamente.

A solicitação do teste durante o pré-natal deve ocorrer acompanhada de aconselhamento pré e pós-teste. Uma vez identificada como portadora do HIV, a gestante deve iniciar o tratamento com a Quimioprofilaxia e o acompanhamento por uma equipe multiprofissional.

Em mulheres grávidas soropositivas para o HIV, o aconselhamento deve prosseguir durante todo o pré-natal, pois essas mulheres enfrentam muitas dificuldades do ponto de vista familiar e social Que dificultam o seguimento das recomendações para a profilaxia da $T V^{(5)}$.

No âmbito das DST/HIV/Aids, o aconselhamento é entendido como uma prática preventiva ampla, Que transcende o âmbito da testagem e contribui para a Qualidade das ações educativas em saúde. Desta forma, pode ser desenvolvido em vários momentos, não devendo se restringir somente ao pré e pós-teste anti-HIV. Além de desempenhar papel fundamental na ampliação da testagem sorológica para o HIV, se reafirma como um campo de conhecimento estratégico para a Qualidade do diagnóstico e da atenção à saúde ${ }^{(6)}$.

A descentralização do aconselhamento e testagem do HIV para a atenção básica tem por objetivo ampliar a cobertura de testagem em gestantes, porém ainda não está ocorrendo com sua capacidade plena. As deficiências encontradas nestes serviços dificultam, sobremaneira o acesso precoce da gestante ao teste anti-HIV, e o aconselhamento não se constitui em uma prática cotidiana devido as limitações técnicas, institucionais e de relacionamento entre profissionais e usuárias $^{(7)}$.

Um resultado positivo para o HIV pode acarretar um grave impacto na vida das mulheres, especialmente euando o diagnóstico ocorre no período gestacional, pois a maternidade se revela como sinal de vida e esperança em contraposição à idéia de morte relacionada à Aids. Porém, os profissionais na atenção básica ainda não se sentem preparados para trabalhar o aconselhamento nestas circunstâncias ${ }^{(7)}$.

Como conseqüência da falta de preparo dos profissionais na atenção básica, esses serviços não oferecem aconselhamento de seguimento à gestante soropositiva independentemente da mesma estar sendo acompanhada em uma unidade de referência o Que pode estar dificultando o seguimento adequado do tratamento pela gestante, devido as muitas dificuldades Que as mesmas têm Que enfrentar e superar.

Por esse motivo, o interesse em realizar este estudo ocorreu a partir da experiência de uma das autoras com aconselhamento de gestantes e identificação das dificuldades enfrentadas pelas gestantes HIV positivas para o seguimento do tratamento e das recomendações para a profilaxia da TV. Sua justificativa está pautada na importância do reconhecimento das experiências e vivências de mulheres HIV positivas, de modo Que possa proporcionar uma reflexão junto aos profissionais de saúde acerca da Qualidade do aconselhamento, visando melhorar a sua relação técnica e pessoal com as usuárias, trazendo conseqüentemente benefícios para o binômio mãe-filho.

\section{METODOLOGIA}

Trata-se de um estudo de abordagem Qualitativa ${ }^{(8,9)}$, desenvolvido em uma maternidade de referência de nível terciário vinculada à Secretaria Estadual de Saúde do Ceará. Essa maternidade recebe gestantes com HIV referenciadas de outras instituições de saúde para realizar o acompanhamento pré-natal e a Quimioprofilaxia para prevenção da TV do HIV.

Trata-se de uma instituição pública Que tem como missão promover e prestar assistência à comunidade, referenciada pelas unidades do Sistema Único de Saúde, e possui elevado nível de resolubilidade, humanização e Qualidade. Desenvolve ações de assistência maternoinfantil e funciona como campo de prática de ensino e pesquisa para alunos do curso de graduação de universidades de Fortaleza ${ }^{(1)}$.

A preferência pela referida unidade ocorreu devido a mesma ter tradição na Qualidade da assistência dispensada ao binômio mãefilho, atuar na assistência à mulher grávida HIV positiva há alguns anos através do Projeto Nascer ${ }^{(2)}$. Ademais, mostrou-se bastante receptiva para o desenvolvimento deste estudo, acreditando Que os resultados poderão trazer benefícios para a melhoria da assistência à gestante soropositiva e, conseQüentemente, para a prevenção da TV do HIV.

Para participar do estudo, as gestantes deveriam estar no $2^{\circ}$ trimestre de gestação, ter recebido mais de duas consultas de prénatal, estar comparecendo regularmente à unidade e fazendo uso da Quimioprofilaxia para prevenção da TV. As puérperas deveriam ter recebido pelo menos duas consultas pré-natais no referido hospital e realizado a Quimioprofilaxia durante o pré-natal. Foram excluídas as menores de 18 anos.

Como instrumento de coleta de dados, foi utilizada a entrevista 
formal e focalizada Que é menos estruturada possível e permite Que o entrevistado fale livremente sobre um determinado assunto. É bastante utilizada com o objetivo de explorar a fundo alguma experiência vivida ${ }^{(8)}$. A coleta de dados foi efetuada nos meses de março e abril de 2006 e as seguintes Questões nortearam todo o processo da entrevista: fale-me da sua experiência de estar grávida com o vírus HIV e do tratamento para evitar a transmissão para o bebê.

Os depoimentos foram gravados após solicitação e esclarecimento acerca dos objetivos da pesQuisa. A limitação do número de entrevistas ocorreu por saturação das respostas.

A análise de dados foi realizada após a transcrição das falas e com base na leitura detalhada das entrevistas. Os dados foram organizados, classificados, agrupados, categorizados ${ }^{(11)}$ e analisados segundo análise de conteúdo ${ }^{(12)}$.

O estudo recebeu aprovação do Comitê de Ética em Pesquisa do Hospital Geral César Cals, como regulamenta a Resolução 196/96 do Conselho Nacional da Saúde/Ministério da Saúde, onde foram respeitados os Quatro referenciais básicos da bioética: autonomia, não-maleficência, beneficência e justiça, entre outros ${ }^{(13)}$.

A fim de garantir legitimidade e resguardar as participantes, foram assegurados bem-estar físico, social e psicológico, bem como a privacidade das informações. As mulheres foram informadas acerca dos objetivos e indagadas se aceitariam participar da pesquisa. Estas assinaram o termo de consentimento livre e esclarecido, Que garantia o anonimato, e ressaltava Que, em nenhum momento, as mesmas seriam prejudicadas no tratamento.

\section{RESULTADOS E DISCUSSÃO}

Participaram do estudo Quatro mulheres Que estavam em acompanhamento no referido hospital, sendo uma gestante e três puérperas. Todas receberam o diagnóstico do vírus HIV entre os anos de 2000 e 2005.

A idade variou de 22 a 31 anos e, Quanto à escolaridade, uma tinha o ensino fundamental incompleto, uma terminou o ensino fundamental, uma tinha o ensino médio incompleto e outra concluiu o ensino médio. No Que diz respeito ao estado civil, três eram casadas ou viviam em união estável e uma era viúva, cujo marido havia falecido recentemente de Aids.

O número de filhos variou de um a três. Quanto à inserção dessas mulheres no mercado de trabalho, uma era auxiliar de vendas e três estavam desempregadas. Com relação ao número de consultas no pré-natal, duas referiram Que realizaram entre cinco e dez consultas e as outras duas, entre dez e Quinze consultas.

Apesar de ser um hospital de referência para acompanhamento pré-natal e parto de mulheres grávidas com HIV, essa demanda é baixa, o Que tornou difícil o acesso a mulheres HIV positivas para as entrevistas. Este fato pode estar relacionado à baixa prevalência de HIV nesta população, a falhas na detecção precoce da infecção na gestação e ao fato de existir outra maternidade para acompanhamento de gestantes HIV positivas. Vale salientar Que nenhuma das mulheres se recusou a participar da entrevista.

A partir da análise aprofundada dos dados, três categorias foram definidas: a revelação do diagnóstico junto aos familiares, as orientações recebidas na unidade e a adesão das recomendações para a profilaxia da transmissão vertical.

\section{A Revelação do Diagnóstico aos Familiares}

Percebeu-se Que algumas dessas gestantes, além de ter Que enfrentar o diagnóstico sofrem muito pela falta de amparo familiar. Estudos mostram Que os familiares consideram necessária a revelação do diagnóstico ${ }^{(14)}$ e apontam a importância do apoio da família ${ }^{(15)}$, especialmente das mães ${ }^{(5)}$, para o enfrentamento das dificuldades trazidas após essa revelação. A família exerce uma importante função no processo de adaptação do portador do HIV ou da pessoa com Aids à nova realidade. Entretanto, nem sempre essas mulheres podem contar com esse apoio. Muitas gestantes resistem em compartilhar o resultado do exame e enfrentam sozinhas muito sofrimento. Nos relatos abaixo, observa-se Que mulheres grávidas HIV positivas enfrentaram situações de desprezo e discriminação por parte da família, dificultando, ainda mais, a maneira de encarar o convívio social.

Eu não Queria chegar pra eles (família) e contar por causa da reação deles, mas só que eu cheguei, ai fiquei pensando, ai contei né! (...) pra minha mãe e pra minha irmã. Desde que eu contei, eu achei elas muito diferentes, não apareceram mais na minha casa. As únicas (pessoas) que me ajudam é do lado do meu pai (EI).

Quando vivenciam o apoio e a presença da família, essas mulheres tornam-se mais preparadas para enfrentar as dificuldades. A aceitação e a adesão ao tratamento podem ser melhoradas com o suporte familiar. Os familiares necessitam, também, conhecer a doença, suas causas, conseQüências, tratamento e os meios de contaminação. Esses conhecimentos fazem com Que os mesmos possam compreender Que o convívio social não põe em risco a sua saúde e, conseQüentemente, percam o receio de serem contaminados. Por outro lado, passam a perceber as especificidades do tratamento.

Me aceitam numa boa (família). Agora rejeição de vizinho, amigos, essas coisas, a gente sente mais, mas a família mesmo (...). Tirando uma tia minha, eu volto atrás, porQue ela é mais assim (...), ela não diz Que tem (preconceito), mas a gente sabe Quando a pessoa tem preconceito com a doença da gente. A gente fica triste, porque logo a família..., mas ela, pra mim tanto faz. Não sendo meus irmãos, pra mim tá bom demais. Só Quem sabe é minha mãe e meu padrasto, mas está tudo tranqüilo. Só Quem sabe do lado dele (marido) é a mãe dele. Mas ela dá apoio, ela é técnica de enfermagem, foi ela Quem incentivou pra gente ir pro hospital (E2).

A gravidez representa um momento de grandes transformações na vida da mulher e requer cuidados especiais. Por isso, faz-se necessária a presença dos familiares neste momento do processo gestacional de uma mulher HIV positiva para Que a mesma se sinta confortada e com condições de realizar o tratamento. As gestantes, de um modo geral, compartilharam o resultado do teste especialmente com a mãe, Que, em algumas situações, demonstra interesse em ajudar e confortar, procurando encontrar forças na fé.

Ela (mãe) já tá mais conformada, diz Que eu não vou morrer que é pra eu rezar. Lá de casa só Quem sabe é minha mãe e minha irmã. Meu pai, Deus me livre de saber (E3).

Por outro lado, é grande a possibilidade do portador do vírus HIV 
sofrer discriminações por parte dos vizinhos e familiares, o Que dificulta a revelação do diagnóstico.

Esse preconceito faz com Que pessoas Que vivem ou convivem com o HIV/Aids tendam a se isolar e está associado aos mitos e crenças existentes na sociedade a respeito da doença ${ }^{(16)}$. Apesar de bastante divulgadas as formas de transmissão, as representações sociais acerca do HIV ainda fazem com Que as pessoas sejam isoladas e passem a ser alvo de recusa por parte de familiares. Os depoimentos a seguir ilustram tal situação:

A gente fica mais assim porQue tem medo do pessoal saber né?..., mas lá em casa só Quem sabe é minha mãe, o meu pai e minha sogra... pronto $(E I)$.

Se afastaram (pais), mal vão lá em casa, (...) a reação deles (...) ficaram assim (...) não falaram nada, aí Quem sabe é meu outro irmão, esse me dá apoio, vai lá em casa, conversa é muito comigo, mas é mais do lado da família dele que dá apoio. Acho que eles ficam com medo de pegar, sei lá! (E2).

O medo de encarar a sociedade e vivenciar o preconceito torna essas mulheres mais suscetíveis a uma série de problemas, especialmente relacionados a Questão do trabalho. Estas, muitas vezes, têm que depender de ajuda financeira de familiares, o Que pode trazer como conseQüência a não realização do tratamento.

Em um dos depoimentos, evidenciou-se a preocupação da mãe em ter Que administrar o xarope ao bebê. Segundo ela, tem Que ocultar os frascos de medicamentos dados a seu filho por medo que outras pessoas pudessem tomar conhecimento da sua patologia, fato corroborado pelos achados de um estudo em Fortaleza com mulheres portadoras do HIV/Aids ${ }^{(17)}$.

... e o pior de tudo é o xarope que tem que dar para a criança, Que tem que dar escondido, tem Que ter o máximo de cuidado, pois Quando tem pessoas em casa, como é Que a gente vai dar....(EI).

Do ponto de vista do parceiro sexual, há uma maior tolerância e aceitação. Percebe-se que os mesmos, após tomarem conhecimento do diagnóstico, oferecem apoio às mulheres, dado encontrado também em um estudo com mulheres grávidas soropositivas em São Paulo ${ }^{(15)}$. Isso pode ser considerado um aspecto bastante positivo e facilitador para o enfrentamento das outras dificuldades que porventura possam aparecer e da adesão ao tratamento. Esse apoio, em algumas situações, ocorreu inclusive em circunstâncias em Que a mulher foi contaminada por um parceiro anterior. Abaixo trechos Que ilustram essa situação:

Ele me ajuda! (marido). Ele é Quem me dá mais força pra eu fazer o tratamento direitinho (E3).

Ele me ajuda, não tem nenhum problema, não". ... ele não tem dificuldade em nada, pelo contrário, sempre me ajuda (marido) (EI).

Ele me apoiava (marido falecido), era ele Que trabalhava, Quem sustentava a família (E4).

Por outro lado, existem situações em Que o conflito é inevitável, especialmente Quando a gestante atribui ao parceiro a contaminação e tem consciência de sua fidelidade ao mesmo.

... eu me chateei muito quando soube, porque tenho certeza que peguei dele. Eu só tive um homem e eu não fui a primeira dele (E3).

\section{O Aconselhamento}

O Ministério da Saúde preconiza Que os profissionais da saúde, ao revelarem o diagnóstico do HIV, especialmente Quando positivo, ofereçam apoio emocional e orientações Que ajudem a amenizar a ansiedade e esclarecer as dúvidas. Dentre essas orientações, destacase como importante: diferença entre o HIV e manifestações da Aids, a disponibilidade do tratamento e sua oferta pelo Sistema Único de Saúde e os cuidados para evitar a possibilidade de transmissão vertical do HIV ${ }^{(18)}$.

O aconselhamento é uma medida importante e deve ser realizado sempre antes e após a realização do teste. No caso específico desse estudo, todas as entrevistadas passaram por um serviço de orientação profissional, onde se destaca a ênfase da adesão ao tratamento, no Que as mesmas não demonstraram dúvidas. Nos depoimentos a seguir, verificou-se o Quanto é importante o acompanhamento realizado por uma equipe multiprofissional, Que pode, de uma forma conjunta, oferecer suporte para o enfrentamento da doença e para a adesão à Quimioprofilaxia.

Ela (médica) disse que eu tomasse na hora certa, não deixasse de tomar. Difícil não foi, porQue elas me explicaram direito (E4).

Lá a gente passa por psicóloga, eles conversam com a gente. Explica Que, no caso da gente ter filho, vai correr o risco da sua filha pegar se você não fizer o acompanhamento direitinho, no caso essa medicação Que eu tava tomando, era justamente pra combater pra não pegar nela (...) né? (E3).

Conversam bastante com a gente, deixam a gente bastante tranqüila. Mas eles conversam, passam horas, toda vez Que você for lá, Que você Quiser conversar com a psicóloga, eles atendem numa boa. Chega com alguma coisa, algum problema, eles estão lá pra receber a gente numa boa (E2).

Esses depoimentos mostram Que, do ponto de vista das orientações e informações, existe uma preocupação dos profissionais para Que a gestante cumpra rigorosamente o tratamento, o Que deve ser considerado positivo. Portanto, vale salientar que as mesmas enfatizam a importância do apoio emocional e do acolhimento às suas demandas, o Que com certeza ajuda na superação das dificuldades.

Estar atento às expressões verbais e não verbais das gestantes $\mathrm{e}$ reconhecê-las como pessoas capazes de resolver os seus próprios problemas são imperativos para uma boa Qualidade da relação profissional paciente. $\mathrm{O}$ profissional tem um importante papel de ajudar no enfrentamento do resultado, nas orientações e disponibilizando-se para colaborar com a usuária, sempre Que necessário.

O medo é um sentimento comum perante a revelação da soropositividade. O profissional de saúde pode oferecer à mulher suporte emocional, capaz de facilitar a revelação do diagnóstico às pessoas com Quem possam compartilhar suas angústias e preocupações. 
As orientações/informações contribuem, sobremaneira, para minimizar os problemas emocionais gerados pelo diagnóstico do HIV, e deveriam ser oferecidas também a todos os familiares das pessoas portadoras.

\section{Adesão às Recomendações para a Profilaxia da Trans- missão Vertical}

É cada vez maior o número de gestantes Que fazem a profilaxia para prevenção da transmissão vertical do HIV, Que garante uma redução drástica na transmissão para o bebê.

A partir de 2001, o Ministério da Saúde passou a recomendar o tratamento de todas as gestantes infectadas pelo HIV $^{(18)}$. Foi verificado Que as mulheres sentem muita dificuldade para seguir o tratamento com a terapia anti-retroviral devido algumas características relativas aos próprios medicamentos e aos seus efeitos colaterais.

\section{... o pior que eu achei foi tomar esses remédios porque eles dão um mal-estar na gente e prejudica o bebê... Tomo 8 h da manhã e 8h da noite... tomo doze comprimidos... é seis de manhã e seis à noite. Tem um remédio que eu tomo que ele é tipo ácido, se você deixar ele desmanchar na sua boca, ele Queima, fica amargando, é o pior. Se você colocar esse remédio na sua mão, num minuto ele se desmancha. Se você deixar na sua boca, ele Queima, dá uma gastura, dá um mal-estar (EI).}

... não é bom não. É um monte de comprimido que eu tenho Que tomar todos os dias e tem um gosto ruim. No começo eu chegava até a vomitar de tanta gastura. É muito ruim mesmo. A boca da gente fica com um gosto estranho (E2).

Diante desses depoimentos, percebe-se o Quanto é importante Que a gestante HIV positiva tenha facilidade de acesso aos profissionais caso enfrente alguma dificuldade no seguimento do tratamento. Neste caso, as consultas de pré-natal não devem seguir intervalos rigorosos e mensais, pois as gestantes Que apresentam efeitos colaterais ou outra dificuldade de adesão podem abandonar o tratamento.

As mulheres adotam diversas estratégias adaptativas para viabilizar o tratamento ${ }^{(5)}$. O diagnóstico precoce, a adesão aos medicamentos e o fato de não amamentar são medidas utilizadas para a redução da transmissão vertical do HIV, e estão acompanhadas dos fatores emocional, social e cultural ${ }^{(19)}$, situações Que não podem ser menosprezadas pelos profissionais de saúde.

De acordo com o Ministério da Saúde, são vários os efeitos colaterais provocados pelo uso de medicações anti-retrovirais ${ }^{18)}$. Esses efeitos são responsáveis, muitas vezes, pelo abandono do tratamento. Duas das principais causas de desistência da terapêutica anti-retroviral é a existência de efeitos colaterais e o conflito na rotina em tomar a medicação ${ }^{(20)}$, Que não podem ser desconsiderados pelos profissionais de saúde durante o aconselhamento.

Por outro lado, o desejo de Que o bebê nasça bem é percebido nos depoimentos. Em geral as mães demonstram disposição em seguir todas as recomendações, mesmo Quando esta oferece algum risco, deixando claro o desejo de uma vida mais saudável para seu(sua) filho(a). É o que se percebe nos relatos abaixo:

Logo Quando eu descobri que estava grávida, eu ia fazer três meses. Eu tava tomando a medicação, Quando eu descobri, ai eles mudaram a medicação. Eu já fazia o tratamento, agora eu tinha Que dobrar né? (..) não faltar nenhuma consulta, nada porQue eu tava ajudando a minha filha, a não transmitir pra ela. Assim fiz até hoje. $\mathrm{O}$ Que depender de mim...(E3).

As mães enfrentam também a dificuldade de não poderem amamentar, pois este ato representa uma forma de interação em Que a mãe tem a possibilidade de transmitir carinho, amor, proteção e saúde ao seu bebê. Esta prática é bastante incentivada às mulheres, entretanto, Quando portadora do vírus HIV, a amamentação torna-se impossibilitada pelo risco oferecido. Para Wiethauper, Cechin e Correia $^{(21)}$, a não amamentação pode acarretar sofrimento para a mãe, pois está sendo impedida de executar uma prática Que traria vários benefícios ao seu filho.

... a gente fica triste porQue a gente vai sabendo Que não vai amamentar de maneira alguma. PorQue o prazer de uma mãe eu acho que é... né? Ter um filho, amamentar, pegar no peito... (E3).

As mulheres soropositivas para o HIV enfrentam várias dificuldades na revelação do diagnóstico, o Que provoca limitações, inclusive para adesão à Quimioprofilaxia para prevenção da transmissão vertical. A impossibilidade de amamentar o bebê acaba resultando em Questões ainda mais conflitantes. Esta situação pode trazer como conseQüência o sentimento de inabilidade na responsabilidade com o cuidado do seu(sua) filho(a) ${ }^{(22)}$.

\section{CONSIDERAÇÕES FINAIS}

Pode-se verificar Que as gestantes portadoras do vírus HIV enfrentaram situações divergentes e conflitantes. A avaliação dessas vivências mostrou Que estes obstáculos resultam em diversos sentimentos negativos.

A família torna-se um ponto fundamental nesse processo por ser a fonte primária no compartilhamento do diagnóstico. No entanto, algumas não recebem o apoio necessário, o Que as fragiliza, tornando-as susceptíveis a distúrbios emocionais, já que a gravidez é um momento em Que as mulheres necessitam de um maior suporte. Outro fator importante constatado foi o apoio oferecido pelo parceiro sexual, facilitando, assim, a adesão ao tratamento para a profilaxia da TV.

Todas as pacientes passaram pelo serviço de aconselhamento, onde receberam orientações sobre a importância do tratamento por profissionais especializados, o Que ficou demonstrado no significativo conhecimento acerca do assunto.

Percebe-se Que a adesão ao tratamento com anti-retrovirais por parte das gestantes sofre influência de uma série de fatores Que são: uso correto dos medicamentos, enfrentamento dos efeitos colaterais e até a ocultação dos remédios dos vizinhos. Portanto, verifica-se o Quanto é importante a implementação de uma equipe multiprofissional no acompanhamento de gestantes soropositivas para o HIV, Que vivenciam o tratamento para a profilaxia da TV, oferecendo a estas mulheres uma assistência mais eficaz e humanizada.

Ouvir a perspectiva das próprias gestantes, com certeza, trará grandes contribuições para o acompanhamento de mulheres grávidas HIV positivas, no Que diz respeito, especialmente, ao aconselhamento. 


\section{REFERÊNCIAS}

I. Ministério da Saúde (BR). Secretaria de Vigilância em Saúde. Boletim Epidemiológico de Aids e DST. Brasília: Ministério da Saúde; 2004.

2. Ministério da Saúde (BR). Coordenação Nacional de DST/Aids. Projeto Nascer. Brasília: Ministério da Saúde; 2003.

3. Cavalcante MS, Ramos Junior AN, Silva TMJ, Pontes LRSK. Transmissão Vertical do HIV em Fortaleza: revelando a situação epidemiológica em uma capital do Nordeste. Rev Bras de Ginecol Obstet 2004; 26 (2): 13 1-7.

4. Connor EM, Sperling RS, Gelber R, Kiselev P, Scott G, O'Sullivan $\mathrm{MJ}$, et al. Reduction of maternal-infant transmission of human immunodeficiency vírus type I with zidovudine treatment. N Engl I Med 1994; 331 (1 18): 1 173-80.

5. Aguiar JM, Simões-Barbosa RH. Relações entre profissionais de saúde e mulheres HIV+: uma abordagem de gênero. Cad Saúde Pública 2006; 22(10): $2115-23$.

6. Ministério da Saúde (BR). Coordenação Nacional de DST/aids. Aconselhamento em DST/HIV/Aids para a Atenção Básica. Brasília: Ministério da Saúde; 2003.

7. Araújo MAL. Avaliação da implementação do aconselhamento e diagnóstico do HIV no pré-natal [tese]. Fortaleza (CE): Universidade Federal do Ceará; 2005.

8. Gil AC. Métodos e técnicas de pesquisa social. São Paulo: Atlas; 1999.

9. Lakatos EM, Marconi MA. Fundamentos de Metodologia Científica. São Paulo: Atlas; 2001.

10. Secretaria de Saúde do Estado do Ceará. Serviços de Saúde: Unidades da rede estadual. Fortaleza; 2004. [citado em 10 set 2005]. Disponível em: http://www.saude.ce.gov.br .

I 1. Rodrigues MSP, Leopardi MT. O método de análise de conteúdo: uma versão para enfermeiros. Fortaleza (CE): Fundação Cearense de Pesquisa e Cultura; 1999.

12. Bardin L. Análise de Conteúdo. Lisboa: Edições 70; 1995.
13. Ministério da Saúde (BR). Conselho Nacional de Saúde. Diretrizes e normas regulamentadoras da peseuisa envolvendo seres humanos: Resolução no. 196/96. Brasília: Ministério da Saúde; 1996.

14. Marques HHS, Silva NG, Gutierez PL, Lacerda R, Ayres JRCM, DellaNegra $\mathrm{M}$, et al. A revelação do diagnóstico na perspectiva dos adolescentes vivendo com HIV/AIDS e seus pais e cuidadores. Cad Saúde Pública 2006; 22(3): 619-29.

15. Feracin ICF. Atitudes e sentimentos das mulheres Que vivenciaram a gravidez e a soropositividade ao vírus HIV [tese]. Campinas (SP): Universidade Estadual de Campinas; 2002.

16. Freitas MRI, Gir E, Rodrigues ARF. Dificuldade sexual vivenciada por mulheres em crise de HIV-I. Rev Latino-Am Enfermagem 2000; 8 (3): 76-83.

17. Galvão MTG, Cerqueira ATAR, Marcondes-Machado J. Avaliação da Qualidade de vida de mulheres através do HATQoL. Cad Saúde Pública 2004; 20 (2): 430-7.

18. Ministério da Saúde (BR). Secretaria de Vigilância em Saúde. Recomendações para a profilaxia da transmissão vertical do HIV e terapia anti-retroviral em gestantes. Brasília: Ministério da Saúde; 2006.

19. Vaz MJR, Barros SMO. Redução da transmissão vertical do HIV: desafio para a assistência de enfermagem. Rev. Latino-Am. Enfermagem 2000; 8 (2): 4I-6.

20. Cardoso GP, Arruda A. As representações sociais da soropositividade e sua relação com a observância terapêutica. Ciênc Saúde Coletiva 2005; 10 (1): 15 1-62.

21. Wiethauper FS, Cechin PL, Correia SG. Aids em gestantes: possibilidade de reduzir a transmissão vertical. Rev Bras Enferm 2003; 56 (3): $221-5$.

22. Paiva SS, Galvão MTG. Sentimentos da não amamentação de gestantes e puérperas soropositivas para HIV. Texto \& Contexto Enferm 2004; 13 (3): 414-9. 